Document downloaded from:

http://hdl.handle.net/10251/170578

This paper must be cited as:

Martí Calatayud, MC.; Evdochenko, E.; Bär, J.; García Gabaldón, M.; Wessling, M.; PérezHerranz, V. (2020). Tracking homogeneous reactions during electrodialysis of organic acids via EIS. Journal of Membrane Science. 595:1-10.

https://doi.org/10.1016/j.memsci.2019.117592

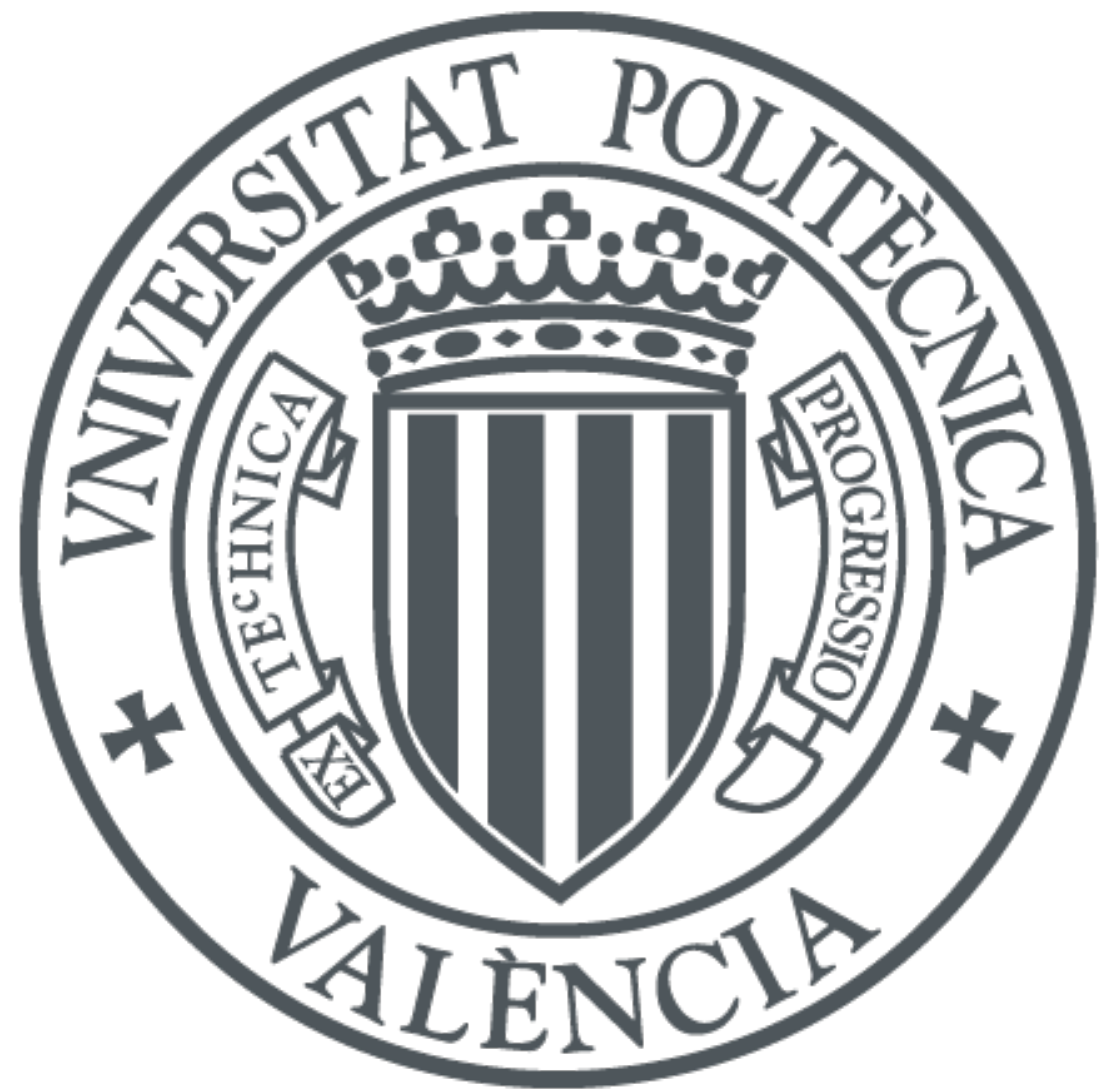

The final publication is available at

https://doi.org/10.1016/j.memsci.2019.117592

Copyright Elsevier

Additional Information 


\title{
Tracking homogeneous reactions during electrodialysis of organic acids via EIS
}

\author{
M.C. Martí-Calatayud ${ }^{\mathrm{a}, *}$, E. Evdochenko ${ }^{\mathrm{b}}$, J. Bär $^{\mathrm{b}}$, M. García-Gabaldón $^{\mathrm{a}}$, \\ M. Wessling ${ }^{\mathrm{b}, \mathrm{c}}$, V. Pérez-Herranz ${ }^{\mathrm{a}}$ \\ ${ }^{a}$ Universitat Politècnica de València, IEC Group, Departament d'Enginyeria Quimica $i$ \\ Nuclear, Camí de Vera s/n, 46022, València, Spain \\ ${ }^{b}$ RWTH Aachen University, Chemical Process Engineering, Forckenbeckstr. 51, 52074 \\ Aachen, Germany \\ ${ }^{c}$ DWI Interactive Materials Research, Forckenbeckstr. 50, 52074 Aachen, Germany
}

\section{Abstract}

Organic acids are highly valuable platform chemicals that can be obtained from bioresources and subsequently transformed into a wide spectrum of profitable consumer goods. After their synthesis, organic acids need to be separated from other by-products and conveniently upconcentrated. Based on the ionic nature of organic acids, electromembrane processes are viable technologies for their recovery. Transport of weak acids through ion-exchange membranes is a complex process influenced by multiple phenomena, i.e. concentration polarization, water dissociation and counterion-membrane interactions. In the present study, the transport of two different organic acids (citric and oxalic acid) through anion-exchange membranes is investigated by means of using linear sweep voltammetry, chronopotentiometry and electrochemical impedance spectroscopy (EIS). Results have shown that, at $\mathrm{pH}$

\footnotetext{
${ }^{*}$ I am corresponding author

Email addresses: mcmarti@iqn.upv.es (M.C. Martí-Calatayud), manuscripts.cvt@avt.rwth-aachen.de (M. Wessling), vperez@iqn.upv.es (V. Pérez-Herranz)
} 
values where multivalent acid anions predominate in solution, a first limiting current density is registered in the current-voltage curves, followed by an increase in membrane resistance. A further increase in current leads to a second limiting current density and a steeper increase in membrane resistance associated with an intensified ion depletion. A strong correlation between polarization curves and electrochemical impedance measurements reveals that such increase in resistance is prompted by generation of $\mathrm{H}^{+}$and $\mathrm{OH}^{-}$ions and the concomitant onset of homogeneous reactions in very thin solution layers. The generation of $\mathrm{H}^{+}$and $\mathrm{OH}^{-}$ions is tracked by a Gerischer arc in the impedance spectra. As the polarization level increases, the subsequent reaction of multivalent anions into lower-charge acid anions involves the evolution of additional Gerischer arcs. Furthermore, the lower conductivity of the reaction products correlates with the increased system resistance. The characteristic times of these reactions are in the order of milliseconds, thus being only directly accessible with the use of frequency response analysis techniques, such as EIS.

Keywords: electrodialysis, weak electrolytes, electrochemical impedance spectroscopy (EIS), platform chemicals, organic acid recovery, biorefinery

\section{Nomenclature}

\section{Abbreviations}

AC Alternate Current

EIS Electrochemical Impedance Spectroscopy

BMED Bipolar Membrane Electrodialysis

DC Direct Current 
ED Electrodialysis

LSV Linear Sweep Voltammetry

\section{Symbols}

$\begin{array}{ll}\omega & \text { Angular frequency } \\ \varphi & \text { Phase shift between voltage and current signals } \\ I(t) & \text { Current as a function of time } \\ I_{0} & \text { Amplitude of the AC component of the current signal } \\ I_{D C} & \text { DC component of the current signal } \\ i_{\text {lim } 1} & \text { First limiting current density } \\ i_{\text {lim } 2} & \text { Second limiting current density } \\ i_{\text {lim }} & \text { Limiting current density } \\ \operatorname{Im}(Z) & \text { Imaginary part of the electrochemical impedance } \\ j & \text { Imaginary unit } \\ R e(Z) & \text { Real part of the electrochemical impedance } \\ U(t) & \text { Voltage as a function of time } \\ U_{0} & \text { Amplitude of the AC component of the voltage signal } \\ U_{D C} & \text { DC component of the voltage signal } \\ Z & \text { Electrochemical Impedance }\end{array}$

1 1. Introduction

2 Sustainable production of specialty chemicals has become an imperative 3 need in modern societies, considering the environmental issues associated 4 with the use of fossil resources as primary source for fuels and daily-use prod5 ucts. Platform chemicals constitute building blocks that are intermediates in 6 the synthesis pathway from raw bio-based materials to final products. They 
are used for the synthesis of engineering plastics, food additives, health-care goods or pharmaceuticals, among others. Despite the notable achievements attained in the fabrication of bio-based products, separation and purification of platform chemicals still pose a prominent limitation in the development of cost-efficient biorefineries $[1,2]$.

Organic acids are an important class of platform chemicals, which can be produced via diverse routes, i.e. catalytic cleavage of biomass, lignin depolymerization or carbohydrate fermentation [3-8]. They form electrolytes in aqueous solutions, giving rise to ionic compounds. Consequently, electromembrane processes, such as electrodialysis (ED), bipolar membrane electrodialysis (BMED)or electrodeionization, have been used for their separation and upconcentration [9-11]. Electromembrane processes are based on the selective permeation of ions through ion-exchangemembranes driven by an electric field. Cation- and anion-exchange membranes are arranged in an alternating fashion to produce concentrated and diluted streams. These processes are recognized as proper technologies for biorefinery production schemes, since they can be coupled with fermentation reactors, imply minimal addition of reagents, can be easily scaled up and powered by renewable sources of energy [12-14].

Transport of organic acids through ion-exchange membranes has been the subject of study of many researches. Most studies are based on batch electrodialysis experiments focusing on optimization of membrane configuration, current density regime or solution pH. A. Chandra et al. determined 
the potential, flow rate and feed concentration that maximized current efficiency during the electrodialytic recovery of citric acid [15]. S. J. Andersen et al. investigated the extraction of short-chain carboxylates from fermentation broths by means of ED coupled with subsequent biphasic esterification [16]. Commonly, sudden drops in current efficiency, jumps in voltage drop or degradation of the membranes are reported during the course of the experiments $[17-20]$. On this subject, a fundamental understanding of the complex events occurring during the recovery of organic acids by ED is lacking.

One of the most relevant phenomena that govern ion transport in electromembrane processes is concentration polarization. As a consequence of membrane selectivity, transport number of counterions through ion-exchange membranes is higher than within the neighboring solution layers. This difference results in the formation of diffusion boundary layers: the concentration of ions in the diluate side next to the membrane decreases, while it increases at the concentrate side. At low polarization levels (low transmembrane voltages), the behavior of the system can be assumed to be quasi-ohmic and the decrease in conductivity at the diluate side is compensated by the increase taking place at the concentrate side. However, as the level of polarization is increased, the concentration gradients at both sides of the membrane become more pronounced. A limit is reached when the concentration at the diluate membrane-solution interface approaches zero: the so-called limiting current density $\left(i_{\text {lim }}\right)$ is reached and the resistance of the system grows considerably. At this point, a further increase in the driving force does not induce a rise in current density, at least until additional mass transfer phenomena supplying 
ions to the membrane are induced. When the membrane voltage drop exceeds a certain threshold, overlimiting mass transfer mechanisms such as electroconvection and water dissociation can come into play. Electroconvection results in the formation of chaotic vortices in the diluted diffusion boundary layer that bring counterions from the bulk towards the membrane surface. Differently, the dissociation of water molecules takes place right at the membrane interface. Both phenomena culminate in an increase in current density beyond the plateau region, leading to the third part of current-voltage curves. In ED of strong electrolytes, electroconvection is usually preferred, since the increase in current is mainly carried by the target solution counterions. However, the development of concentration polarization in weak electrolytes is a more complex process, owing to the presence of multiple counterions, which can participate in equilibrium reactions with the products of water dissociation.

The treatment commonly adopted for ED of strong electrolytes, a wellestablished process, cannot be extrapolated by default for ED of organic acids. Contrary to strong electrolytes, where salts are fully dissociated in their forming ions, organic acids are weak electrolytes and only dissociate partially into their respective anions and cations. Mainly solution $\mathrm{pH}$, but also total electrolyte concentration or presence of coions determine the electrolyte speciation and, in turn, the type and amount of current carriers. Extensive investigations about transport of weak electrolytes of inorganic nature has shown that shifts in the equilibrium are concomitant to variations in the level of applied current density [21-25]. Most importantly, such 
changes may imply a variation in the resistance of membrane systems, which are manifested in the form of atypical current-voltage curves $[24,25]$. In this vein, Melnikova et al. identified two plateau regions relating to two different limiting current densities, and attributed the first limiting current to the depletion of ions at the membrane surface [26]. Above the first limiting current, acid anions dissociated as they entered the membrane, releasing $\mathrm{H}^{+}$ions at the depleted membrane/solution interface and $\mathrm{OH}^{-}$ions at the concentrate membrane/solution interface. The resulting $\mathrm{H}^{+}$and $\mathrm{OH}^{-}$ions, caused a rise in current density, until the membrane was almost completely converted into the multivalent anion form. Rybalkina et al. reported similar effects with phosphoric acid anions [27].The peculiar current-voltage curves obtained for organic acids have been likewise reproduced in 1-dimensional mechanistic simulations [28]. In this regard, it is important to take into account two trends observed in the literature, which are of special relevance for the present investigation. First, it has been widely confirmed that anionexchange membranes are more prone to induce catalytic water dissociationthan cation-exchange ones [29-31]. Second, the dissociation of water at high current densities hampers the progress of electroconvection, because the generated $\mathrm{H}^{+}$and $\mathrm{OH}^{-}$ions access the space charge region developed at the membrane-solution interface [32-34].

Current efficiency and membrane voltage drops are key indicatorsof the yield and energy consumption of electromembrane processes, respectively. Systematic analysis by means of sound and precise techniques is therefore necessary to give insight into the mass transfer phenomena involved during 
the transport of organic acids through ion-exchange membranes at different current densities. Getting a better understanding on the interplay between the involved factors and controlling the performance of ED of weak electrolytes is a central milestone in the design of optimum downstream processing of organic acids. In the present work, the current-voltage relationship describing the migration of organic anions through permselective membranes is studied in depth via Electrochemical Impedance Spectroscopy (EIS). EIS is a frequency response analysis technique applicable to decomposing the resistance of electrochemical systems into several contributions, each of them being associated with mass transfer phenomena showing up at different characteristic times.

\section{Experimental}

\subsection{Electrolytes and membranes}

Two organic acids with different number of carbon atoms and carboxylic groups have been selected for the present investigation: citric acid and oxalic acid. Solutions from the acid and sodium salt forms of both were prepared from the following reagents: $\mathrm{H}_{2} \mathrm{C}_{2} \mathrm{O}_{4} \cdot 2 \mathrm{H}_{2} \mathrm{O}, \mathrm{Na}_{2} \mathrm{C}_{2} \mathrm{O}_{4}, \mathrm{C}_{6} \mathrm{H}_{8} \mathrm{O}_{7}$ and $\mathrm{C}_{6} \mathrm{H}_{5} \mathrm{Na}_{3} \mathrm{O}_{7} \cdot 2 \mathrm{H}_{2} \mathrm{O}$, all supplied by Panreac Química SLU (Spain). For the sake of readability, the anion of citric acid, citrate $\left(\mathrm{C}_{6} \mathrm{H}_{5} \mathrm{O}_{7}^{3-}\right)$, will be referred to as $\mathrm{Cit}^{3-}$ in this work. Analogously, the oxalate anion $\left(\mathrm{C}_{2} \mathrm{O}_{4}^{2-}\right)$ will be referred to as $\mathrm{Ox}^{2-}$. Both organic acids exhibit the attributes of weak electrolytes: they do not dissociate completely in aqueous solutions into their respective anions and cations. Citric acid is a triprotic acid that can undergo 
successive deprotonation reactions, as shown below:

$$
\begin{aligned}
& \mathrm{H}_{3} \mathrm{Cit} \rightleftharpoons \mathrm{H}_{2} \mathrm{Cit}^{-}+\mathrm{H}^{+} \\
& \mathrm{H}_{2} \mathrm{Cit}^{-} \rightleftharpoons \mathrm{HCit}^{2-}+\mathrm{H}^{+} \\
& \mathrm{HCit}^{2-} \rightleftharpoons \mathrm{Cit}^{3-}+\mathrm{H}^{+}
\end{aligned}
$$

with $p K a_{1}, p K a_{2}$ and $p K a_{3}$ values of $3.128,4.761$ and 6.396 , respectively $\left(25^{\circ} \mathrm{C}\right)$. Furthermore, $\mathrm{Cit}^{3-}$ ions may combine with $\mathrm{Na}^{+}$ions according to:

$$
\mathrm{Cit}^{3-}+\mathrm{Na}^{+} \rightleftharpoons \mathrm{NaCit}^{2-}
$$

120 where $\log K=1.4$.

Oxalic acid is a dicarboxylic acid, which can lose up to two protons:

$$
\begin{aligned}
& \mathrm{H}_{2} \mathrm{Ox} \rightleftharpoons \mathrm{HOx}^{-}+\mathrm{H}^{+} \\
& \mathrm{HOx}^{-} \rightleftharpoons \mathrm{Ox}^{2-}+\mathrm{H}^{+}
\end{aligned}
$$

The $p K a_{1}$ and $p K a_{2}$ values corresponding to reactions 5 and 6 are 1.252 and 4.266, respectively [35]. Oxalate anions can also recombine with $\mathrm{Na}^{+}$ according to the following equilibrium:

$$
\mathrm{Ox}^{2-}+\mathrm{Na}^{+} \rightleftharpoons \mathrm{NaOx}^{-}
$$

where $\log K=0.9$.

The equilibrium diagrams of the $\mathrm{H}_{3} \mathrm{Cit} / \mathrm{Na}_{3} \mathrm{Cit}$ and $\mathrm{H}_{2} \mathrm{Ox} / \mathrm{Na}_{2} \mathrm{Ox}$ systems 
are plotted in Fig. 1 for a wide range of $\mathrm{pH}$ values. The undissociated acid forms predominate at very low $\mathrm{pH}$ values, while the formation of multiply charged anions is favored at increasing $\mathrm{pH}$ values. Moreover, here it is to be noted that, in the membrane phase, the presence of complex species of $\mathrm{NaOx}^{-}$ is less likely to occur than in solution because of the exclusion of $\mathrm{Na}^{+}$ions by the membrane fixed charges.In order to investigate the effect of the predominating species on ion transport through the membranes, different mixtures of the acids and their corresponding salts were prepared in distilled water at a total concentration of either $\mathrm{Cit}^{3-}$ or $\mathrm{Ox}^{2-}$ species of $0.05 \mathrm{M}$. The dashed vertical lines in the speciation diagrams indicate the $\mathrm{pH}$ of the working solutions prepared. Depending on the method used to obtain organic acids from biomass, the ED feed solutions coming from previous fermentation broths can cover a wide $\mathrm{pH}$ spectrum $[9,15,36,37]$. In addition to organic acid solutions, electrochemical measurements were also conducted with $0.05 \mathrm{M}$ $\mathrm{NaCl}$ solutions, and were taken as a reference of a strong electrolyte for comparison purposes.

The limiting step during the recovery of organic acids is the transport of the acid anions through anion-exchange membranes. Consequently, this will be the main subject of study in the present work. Commercial anionexchange membranes HDX200 (Ionsep-HC-A, supplied by Hidrodex) were used for this investigation. These membranes have a heterogeneous structure with reinforcing fabrics and have a concentration of 1.8 meq of quaternary amine groups per gram of membrane. The diluate compartments of the ED experimental setup is separated from the cathode by HDX100 cation- 
a)

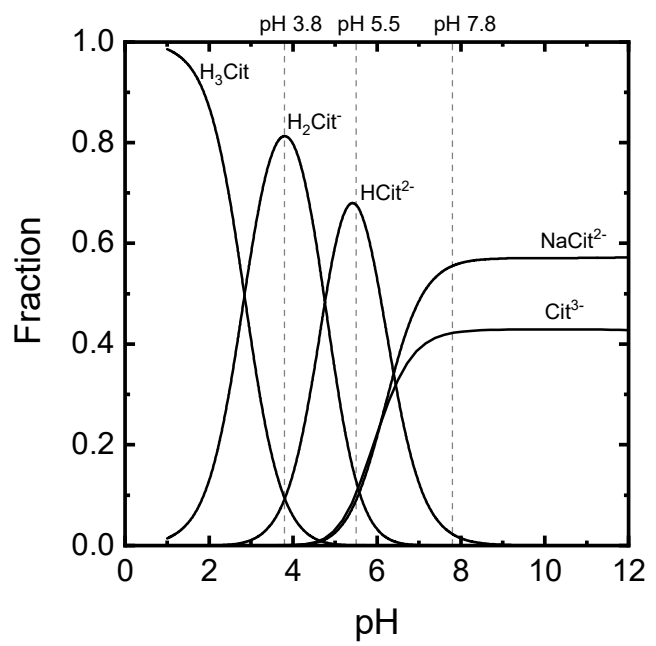

b)

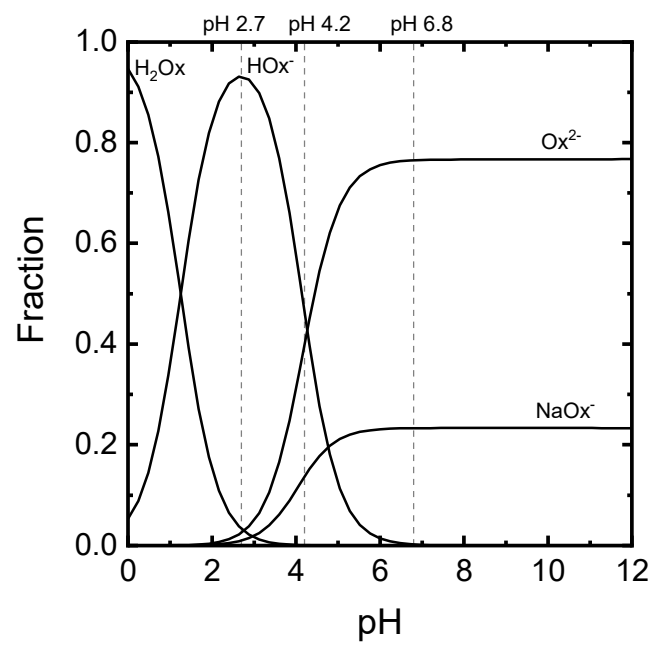

Figure 1: Speciation diagrams for (a) $0.05 \mathrm{M} \mathrm{H}_{3} \mathrm{Cit} / \mathrm{Na}_{3} \mathrm{Cit}$ solutions and (b) $0.05 \mathrm{M}$ $\mathrm{H}_{2} \mathrm{Ox} / \mathrm{Na}_{2} \mathrm{Ox}$ solutions.

Table 1: Properties of the ion-exchange membranes used in the present work.

\begin{tabular}{ccccc}
\hline ion-exchange membrane & fixed charged group & ion-exchange capacity (meq/gr) & thickness $(\mathrm{mm})$ & water uptake \\
\hline IONSEP-HC-A & quaternary amine & 1.8 & 0.42 & $40 \%$ \\
IONSEP-HC-C & sulfonic acid & 2.0 & 0.42 & $40 \%$ \\
\hline
\end{tabular}

exchange membranes (Ionsep-HC-C). The properties of both membranes are summarized in 1.

\subsection{Experimental setup for the electrochemical measurements}

The electrochemical measurements performed in this work were conducted using a four electrode configuration. The setup consisted of three compartments, each one with $130 \mathrm{~mL}$ volume capacity, separated by ion exchange membranes, which is described in detail in previous publications [38, 23]. The 
anion-exchange membrane had an effective membrane area of $1 \mathrm{~cm}^{2}$ and was equilibrated with the electrolyte solution overnight prior to the experiments. Voltage was recorded between a pair of $\mathrm{Ag} / \mathrm{AgCl}$ reference electrodes. These were immersed in luggin capillaries, installed at both sides of the membrane under study. The working and counter electrodes consisted of two graphite bars placed at the anodic and cathodic compartments, respectively. The three compartments were completely filled with the measuring solution and experiments were conducted at room temperature. All electrochemical measurements were performed using a potentiostat/galvanostat from Metrohm, model Autolab PGSTAT302N. Results were sampled and treated with the software Nova v. 2.1.

\subsection{Current-voltage behavior}

Linear sweep voltammetry (LSV) and chronopotentiometry were conducted to obtain the current-voltage behavior of the membrane-electrolyte systems. LSV measurements were applied by increasing the potential up to $3 \mathrm{~V}$ at a scan rate of $5 \mathrm{mV} / \mathrm{s}$. Meanwhile, the resulting current was sampled. Subsequently, we identified characteristic regions of the polarization curves and conducted various chronopotentiometric measurements in each of them. For every investigated point of the curves, a constant current was applied for $300 s$ and the resulting potential drop was recorded. Afterward, the current was set to zero and the relaxation phase was recorded for $100 \mathrm{~s}$ before moving on to the next measurement point. 


\subsection{Impedance measurements}

Further analysis at selected working points corresponding to different regions of the polarization curves were performed through EIS. A sinusoidal voltage was imposed to the system over a given voltage bias. The frequency range of the impedance experiments was $10^{5} \mathrm{~Hz}$ to $2.5 \mathrm{mHz}$ and the voltage amplitude was $10 \mathrm{mV}$. The amplitude was chosen to be high enough to minimize noise effects and small enough to comprise a range of linear current-voltage behavior. High frequencies (until $10 \mathrm{~Hz}$ ) were measured at least three times to improve accuracy, while the measurement time at frequencies smaller than $50 \mathrm{mHz}$ was increased to $100 \mathrm{~s}$.

The input voltage signal imposed to the system takes the following form:

$$
U(t)=U_{D C}+U_{0} \cdot \sin (\omega t)
$$

where $U(t)$ represents the total voltage, $U_{D C}$ is the DC component, and $U_{0}$ and $\omega$ stand for the amplitude of the $\mathrm{AC}$ component and the angular frequency, respectively. When $U_{0}$ is small enough, the behavior of the system is linear and the electric current through the system will respond with a sinusoidal function with the same frequency, but displaced in time:

$$
I(t)=I_{D C}+I_{0} \cdot \sin (\omega t+\varphi)
$$

where $I_{D C}, I_{0}$ and $\varphi$ represent the DC component of the current signal, the amplitude of the AC component of current and the phase shift between $U(t)$ and $I(t)$ signals. The impedance of the system, $Z$, is given by the following 
equation:

$$
Z=\frac{U_{0}}{I_{0}} \cdot e^{j \varphi}
$$

where $j=\sqrt{-1}$ is the imaginary unit. The impedance can also be expressed in the form of a complex number, as the sum of a real component, $\operatorname{Re}(Z)$, and an imaginary component, $\operatorname{Im}(Z)$ :

$$
Z=\operatorname{Re}(Z)+j \cdot \operatorname{Im}(Z)
$$

$\operatorname{Re}(Z)$ represents the resistance of the system and $\operatorname{Im}(Z)$ the reactance. Impedance spectra is usually represented graphically in the form of Nyquist plots, where the negative imaginary part of the impedance, $-\operatorname{Im}(Z)$, is plotted over its real part, $\operatorname{Re}(Z)$.

\subsection{Measurement of conductivity as function of $p H$}

The conductivity as a function of $\mathrm{pH}$ for $\mathrm{H}_{3} \mathrm{Cit} / \mathrm{Na}_{3} \mathrm{Cit}$ and $\mathrm{H}_{2} \mathrm{Ox} / \mathrm{Na}_{2} \mathrm{Ox}$ systems was determined by means of titration. Their respective salts were prepared at a concentration of $0.05 \mathrm{M}$. The corresponding acid was prepared at the same concentration, in order to ensure constant concentration of anions. $100 \mathrm{~mL}$ of the salt solution were stirred at room temperature $\left(21^{\circ} \mathrm{C}\right)$ and two electrodes were placed inside the solution to measure $\mathrm{pH}$ and conductivity. Subsequently, acid solution was poured in small volume steps, while $\mathrm{pH}$ and conductivity were registered. 
a)

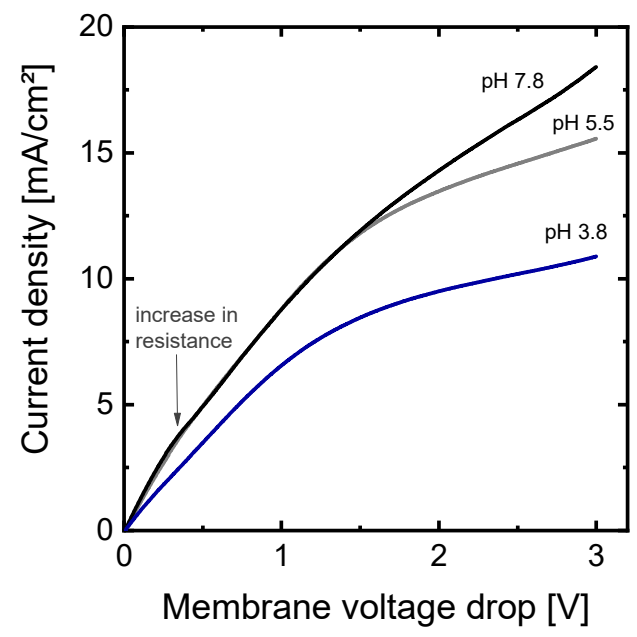

b)

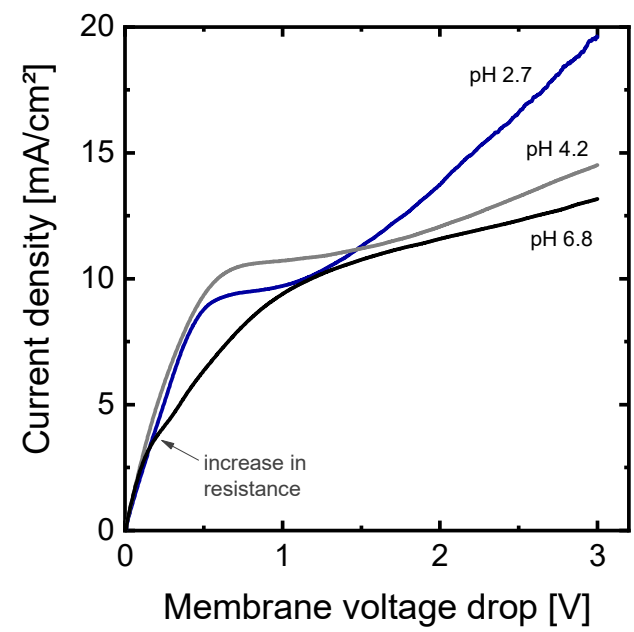

Figure 2: Current-voltage curves registered at different values of $\mathrm{pH}$ for (a) $0.05 \mathrm{M}$ $\mathrm{H}_{3} \mathrm{Cit} / \mathrm{Na}_{3}$ Cit solutions and (b) $0.05 \mathrm{M} \mathrm{H}_{2} \mathrm{Ox} / \mathrm{Na}_{2} \mathrm{Ox}$ solutions.

\section{Results}

\subsection{Current-voltage characteristics}

Current-voltage measurements conducted by linear sweep voltammetry for the two electrolyte systems, $\mathrm{H}_{3} \mathrm{Cit} / \mathrm{Na}_{3} \mathrm{Cit}$ and $\mathrm{H}_{2} \mathrm{Ox} / \mathrm{Na}_{2} \mathrm{Ox}$, at different $\mathrm{pH}$ values are presented in Fig. 2. From the plots, it is evident that solution $\mathrm{pH}$ has a strong influence on the shape of the curves. For both systems, the curves obtained at acidic $\mathrm{pH}$ show the three characteristic regions typically obtained with strong electrolytes. First, at very low current densities, the current-voltage relationship is well described by a quasi-ohmic dependence, since membrane voltage drop increases linearly with current density. As the level of polarization is increased, depletion of ions at the diluting diffusion boundary layer involves a decrease in the concentration of ions from the bulk solution up to the membrane-solution interface. This decrease in concen- 
tration is evidenced in the current-voltage curves in the form of a plateau region, thus reflecting the increased resistance of the system. The current density that marks the beginning of the plateau region, commonly termed as the limiting current density, $i_{\text {lim }}$, appears at about $7.5 \mathrm{~mA} / \mathrm{cm}^{2}$ for the $\mathrm{H}_{3} \mathrm{Cit} / \mathrm{Na}_{3} \mathrm{Cit}$ solution having a $\mathrm{pH}$ of 3.8. In the case of the $\mathrm{H}_{2} \mathrm{Ox} / \mathrm{Na}_{2} \mathrm{Ox}$ solutions at $\mathrm{pH} 2.7$ and 4.2 , the $i_{\text {lim }}$ takes values around 8.5 and $9.5 \mathrm{~mA} / \mathrm{cm}^{2}$, respectively. The third region appearing at high current densities is characterized by an increase in the slope as a consequence of an enhanced supply of ions to the membrane depleting interface. As indicated in the introduction, overlimiting mass transfer phenomena include the dissociation of water and the onset of electroconvective vortices that produce mixing in the diffusion boundary layer. The third region can be clearly seen for the $\mathrm{H}_{2} \mathrm{Ox} / \mathrm{Na}_{2} \mathrm{Ox}$ system at a $\mathrm{pH}$ of 2.7. On the contrary, for the $\mathrm{H}_{3} \mathrm{Cit} / \mathrm{Na}_{3} \mathrm{Cit}$ system, overlimiting regions are not clearly seen within the range of applied voltages.

The polarization curves registered for solutions at the highest $\mathrm{pH}$ values (pH of 5.5 and 7.8 in Fig. 2(a) and pH of 6.8 in Fig. 2(b)) display an atypical evolution. Similar to results reported in previous publications dealing with weak electrolytes, more than two bending points (two $i_{l i m}: i_{l i m 1}$ and $i_{l i m 2}$ ) can be detected [24, 26, 39]. After the initial region of quasi-ohmic behavior, a first increase in membrane resistance is observed. This phenomenon occurs at current density values around $3.5 \mathrm{~mA} / \mathrm{cm}^{2}$ for both systems. As the current density is further increased, a tilted plateau is registered until another bending of the curves takes place. From this point on, the curves exhibit a second plateau, significantly flatter than the previous one. Given the flat- 
ness and length of the second plateaus formed at $i>i_{l i m 2}$, electroconvection seems to play a minimal role at the range of DC bias applied in the present work. If the curves obtained at high and low $\mathrm{pH}$ values are compared in this range of current densities, it is clear from the plots that the second plateau evolves almost parallel to the only plateau registered in acidic conditions. This fact indicates that in both cases the phenomenon causing the increased system resistance is the same: the depletion of ions near the membrane when $i>i_{\lim 2}$. On the contrary, the phenomenon responsible for the $i_{l i m 1}$ remains unclear at this point.

To further investigate the progress of concentration polarization, especially at current densities between $i_{l i m 1}$ and $i_{l i m 2}$, chronopotentiometric measurements were carried out for each system. The chronopotentiograms are representations of the timely evolution of the membrane voltage drop, at constant current conditions, until a steady state is reached. Fig. 3 shows the correlation between the chronopotentiometric and the LSV measurements for $0.05 \mathrm{M} \mathrm{Na}_{3} \mathrm{Cit}$ solutions. The chronopotentiograms show the typical profile reported for strong electrolytes: at low current densities (e.g. $3 \mathrm{~mA} / \mathrm{cm}^{2}$ ), only the quasi-ohmic resistance of the system is visible and the curves exhibit a flat response; as the $i_{l i m 1}$ is reached, a sharp increase in voltage illustrates the development of concentration polarization. The last values of membrane voltage drop of the chronopotentiograms are representative for the steady state of the system. Thus, they can be represented against the corresponding current density to obtain the polarization curves. As can be seen in Fig. 3 (b), these representations are equivalent to the measurements con- 
a)

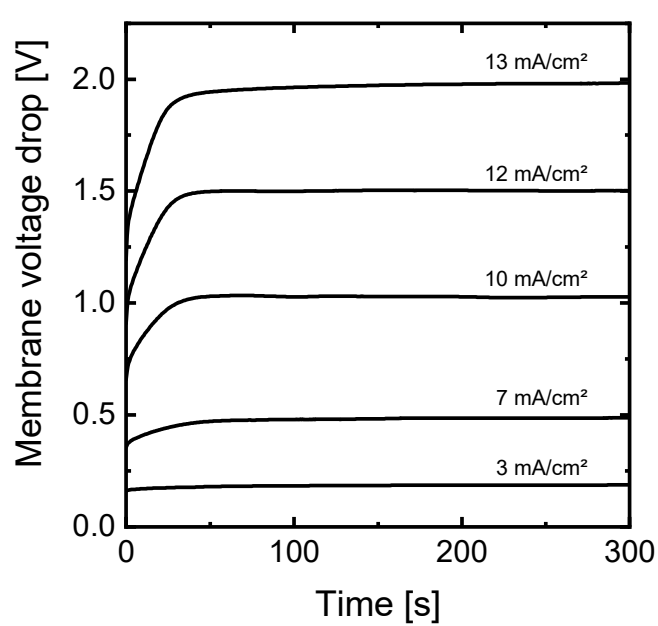

b)

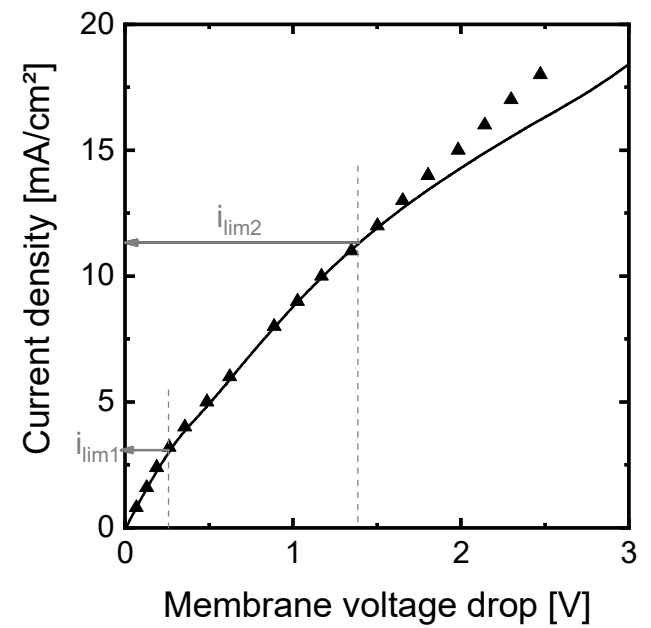

Figure 3: Comparison between the registered (a) chronopotentiograms and (b) the currentvoltage curves for the $0.05 \mathrm{M} \mathrm{Na}_{3}$ Cit solutions having a $\mathrm{pH}$ value of 7.8 .

Despite the agreement between chronopotentiometry and LSV, no un- 
a)

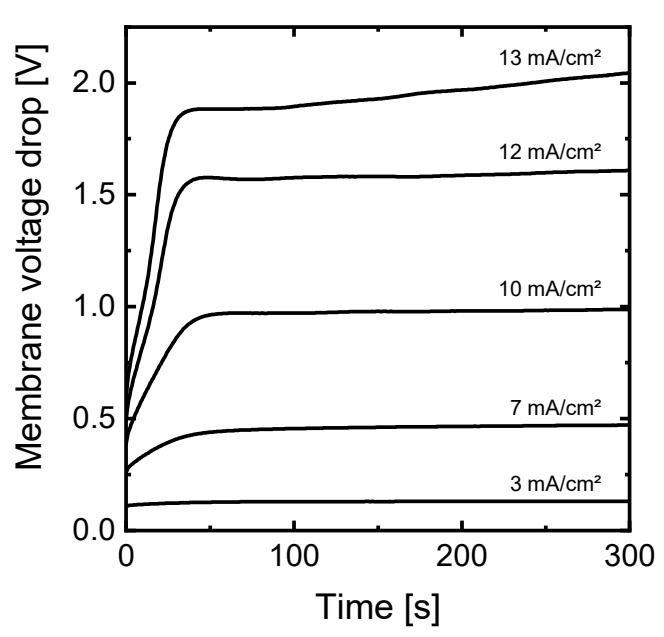

b)

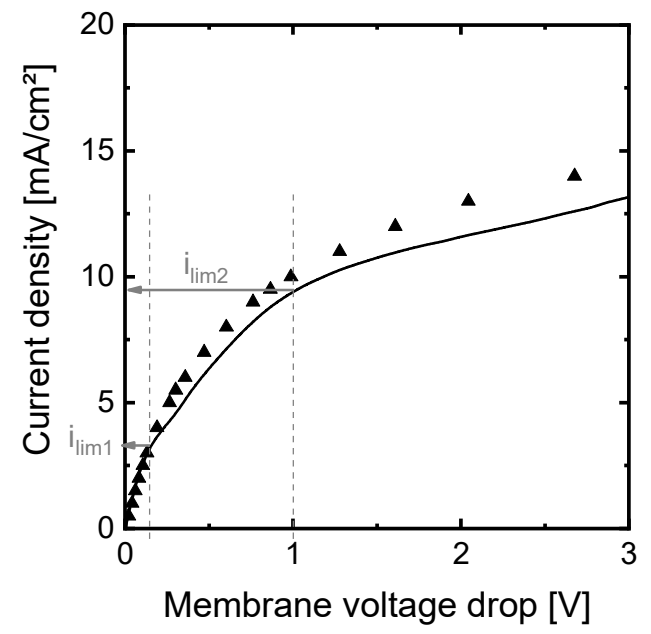

Figure 4: Comparison between the registered (a) chronopotentiograms and (b) the currentvoltage curves for the $0.05 \mathrm{M} \mathrm{Na}_{2} \mathrm{Ox}$ solutions having a $\mathrm{pH}$ value of 6.8 .

system resistance at currents between $i_{\text {lim } 1}$ and $i_{\text {lim2 } 2}$ can be extracted from the chronopotentiograms. This differs from previous studies, where useful information on different mass transfer processes could be obtained by means of chronopotentiometry $[25,40]$. This fact reveals that the timescale at which such phenomenon takes place is probably shorter than the resolution of the measuring time. Hence, supportive information gathered from more powerful techniques which allow it to accurately access to phenomena that undergo at different rates is needed. To tackle this challenge, in the following section, EIS measurements will be analyzed for the elucidation of the physical phenomena that are behind the particular features observed during ED of organic acids. 


\subsection{Electrochemical impedance spectroscopy measurements at different cur-} rent regimes

Electrochemical impedance measurements were conducted at different levels of potential bias, which were selected to fall within the characteristic regions of the polarization curves. EIS is based on the measurement of the relationship between the sinusoidal voltage and current signals registered between two points of a system at a wide range of frequencies. One of the main potentials of EIS is the identification of distinct mass transfer phenomena that are included in the global DC response of the system, but develop at different characteristic frequencies upon application of AC signals.

More specifically, the rates of ion transport across an electrochemical cell may differ based on the dielectric and conducting properties of each slab of the system. Previous experimental works on the impedance response of ion-exchange membranes typically showcase two main contributions to ion transport, which are described by two distinctive arcs in Nyquist diagrams [41-43]:

- A geometric arc appearing at the left side of the plots (high frequencies), which is associated with the ohmic conductivity of membrane and electrolyte.

- A diffusion arc appearing at the right side of the plots (low frequencies). This arc follows a $45^{\circ}$ slope at medium frequencies and evolves into a semicircle as frequency tends to zero.

Depending on factors, such as the flow regime, the ion concentration or the 


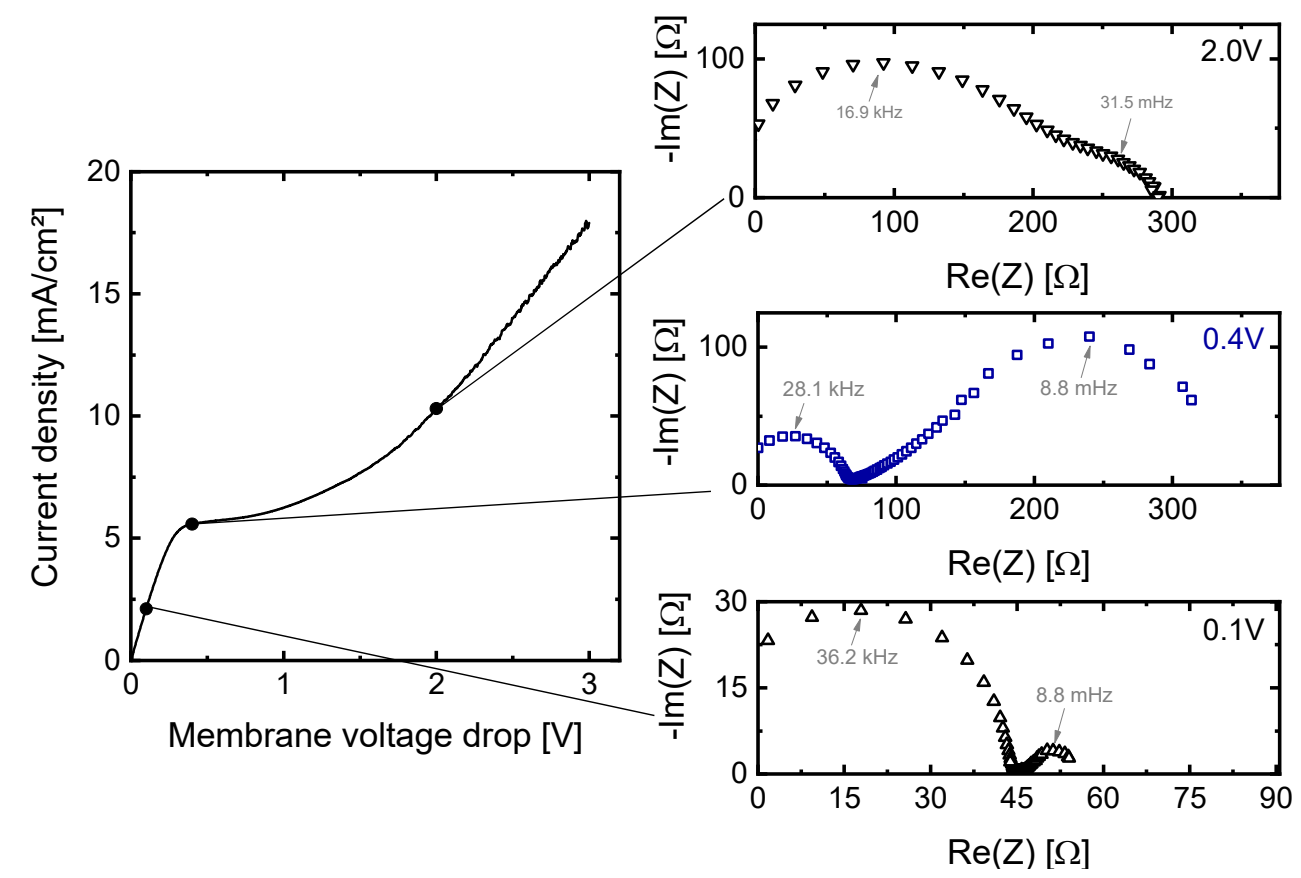

Figure 5: Current-voltage curve and EIS spectra obtained at different current regimes for $0.05 \mathrm{M} \mathrm{NaCl}$ solutions and the HDX200 membrane.

In the plot corresponding to the quasi-ohmic region, the geometric semi- 
circle accounts for the major part of the system resistance, whereas the Warburg-type diffusion impedance is significantly smaller. These results are consistent with the low level of polarization achieved at $0.1 \mathrm{~V}$, where the concentration profiles in the diffusion boundary layers are not fully developed. In this regime, diffusive limitations are not important yet, so that the main resistance to ion transport is associated with the migration of ions. An important parameter that can be obtained from each semicircle is the characteristic frequency. As indicated in the plots, the characteristic frequency corresponds to the measuring point at which the maximum of a semicircle is registered (i.e. the maximum in $-\operatorname{Im}(Z)$ ). The inverse of this frequency represents the time constant of the process that is tracked by the semicircle in question. Time constants indicate how fast processes involved during ion transport occur until a new steady state of the membrane system is attained. The Nyquist plot obtained at DC bias of $0.1 \mathrm{~V}$ has two characteristic frequencies, $36.2 \mathrm{kHz}$ for the geometric and $8.8 \mathrm{mHz}$ for the Warburg arc, thus reflecting that diffusive processes develop significantly slower than ion migration.

When the DC bias is increased beyond the $i_{\text {lim }}$, the diameter of the Warburg semicircle grows substantially, becoming the predominant resistance in the system. Here, it is to note that the scale of the graph has been adapted to properly show the total system resistance. In the plateau region after surpassing the $i_{l i m}$, concentration profiles should have been fully developed. Accordingly, the concentration of ions at the diluate membrane/solution interface tends to zero, so that the main resistance to ion transport is located 
in this part of the system.

The spectrum obtained at DC bias corresponding to the region of overlimiting current densities displays two overlapping arcs. According to the shape of the current-voltage curves, the current density rises again with the membrane voltage drop, which implies that the supply of anions to the membrane surface has been triggered. It is also noteworthy, that the overall membrane resistance, which can be extracted from the intercept with the $\mathrm{x}$-axis at very low frequencies, is lower than the resistance obtained at DC of $0.4 \mathrm{~V}$ (plateau region). The characteristic frequency of the second arc is close to $31.5 \mathrm{mHz}$, notably differing from the frequencies associated with a Warburgtype impedance. Thus, the catalytic dissociation of waterand the transport of $\mathrm{OH}^{-}$ions through the membrane seems to be the reason for the reduction in resistance and the presence of the second arc. The dissociation of water in anion-exchange membranes at overlimiting currents has been studied via EIS by Kniaginichieva et al [44]. It was found that all arcs of Nyquist plots merge at current densities higher than $1.5 \cdot i_{\text {lim }}$. The results shown in the upper-right panel of Fig. 5 follow this trend. In this case, the current transfer across the membrane is carried by the product ions of water dissociation, so that the diffusion limitation is not apparent in the plots as it was for lower DC bias.

Following with the impedance spectra obtained with organic acids at different current density regimes, Fig. 6 shows the Nyquist plots obtained for $\mathrm{Na}_{3} \mathrm{Cit}$ solutions. At very low polarization levels $\left(i<i_{l i m 1}\right)$, the spectrum 
obtained is analogous to those previously described for strong electrolytes. Both the geometric and diffusive arcs become evident and are well separated from each other in the plots. Furthermore, the characteristic frequencies correspond to the same range of frequencies that are distinctive of migrationand diffusion-limited mass transfer processes.

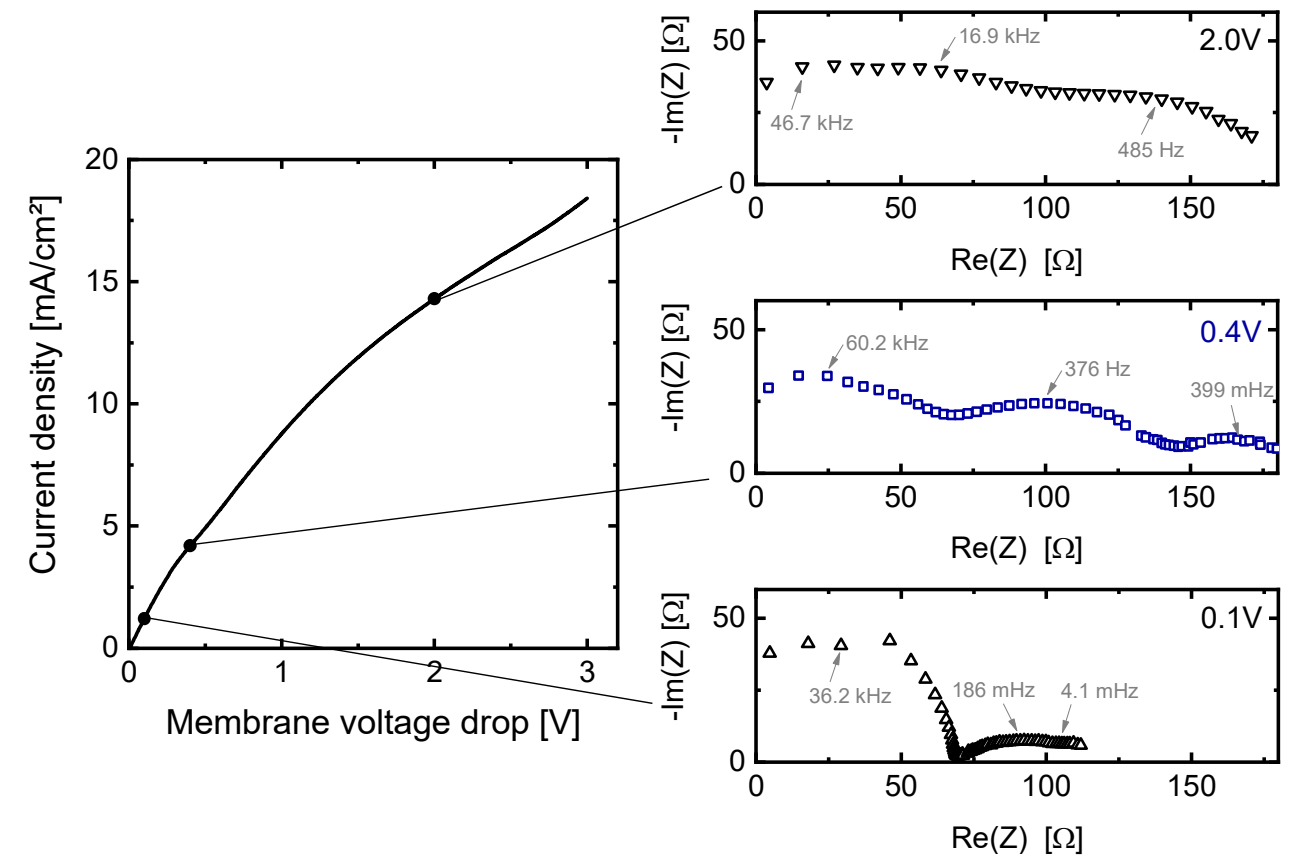

Figure 6: Current-voltage curve and EIS spectra obtained at different current regimes for $0.05 \mathrm{M} \mathrm{Na}_{3}$ Cit solutions with a $\mathrm{pH}$ of 7.8 .

When the background DC bias is slightly increased up to $0.4 \mathrm{~V}$ and the first tilted plateau is reached (characteristic of organic acids at high $\mathrm{pH}$ values, i.e. $\left.i_{\lim 1}<i<i_{\lim 2}\right)$, the shape of the impedance spectrum undergoes notorious changes. The plots contain interesting features not observed with strong electrolytes. In this case, the spectrum presents three different 
semicircles, which are slightly overlapped with each other. While the arc appearing in the left has a characteristic frequency in the same order of magnitude as the geometric arcs observed at lower DC voltages, the characteristic frequencies of the second and third arc do not belong to the timescales of diffusion-controlled processes. Moreover, the phenomena associated with the emergence of the two additional arcs at medium frequencies causes an increase in the overall system resistance.

A further increase in DC bias to fall in the second plateau region $(i>$ $\left.i_{\text {lim2 } 2}\right)$ results in impedance spectra with similar shape as in the second plateau region. The three different arcs can be hardly identified because the overlapping between them becomes stronger. In this case, the maxima of the second and third arc are displaced toward higher frequencies. The characteristic frequency changes from $376 \mathrm{~Hz}$ to $16.9 \mathrm{kHz}$ for the middle arc and from $399 \mathrm{mHz}$ to $485 \mathrm{~Hz}$ for the third arc, when increasing the DC bias level from 0.4 to $2 \mathrm{~V}$. The shifts indicate that the processes associated with the middle-frequency arcs speed up with an increase in the polarization level.

The impedance spectra obtained with $\mathrm{Na}_{2} \mathrm{Ox}$ solutions are shown in Fig. 7. In this case, Nyquist plots evolve similarly as for $\mathrm{Na}_{3} \mathrm{Cit}$ solutions, where additional arcs appear at increasing DC bias, and then, at the highest applied voltages, all arcs merge into a distorted semicircle. It has to be noted that the arcs appearing at intermediate frequencies may be more or less evident based on the different equilibrium reactions taking place in each system. In this sense, $\mathrm{H}_{3} \mathrm{Cit}$ is a tricarboxylic acid and can generate mixtures 


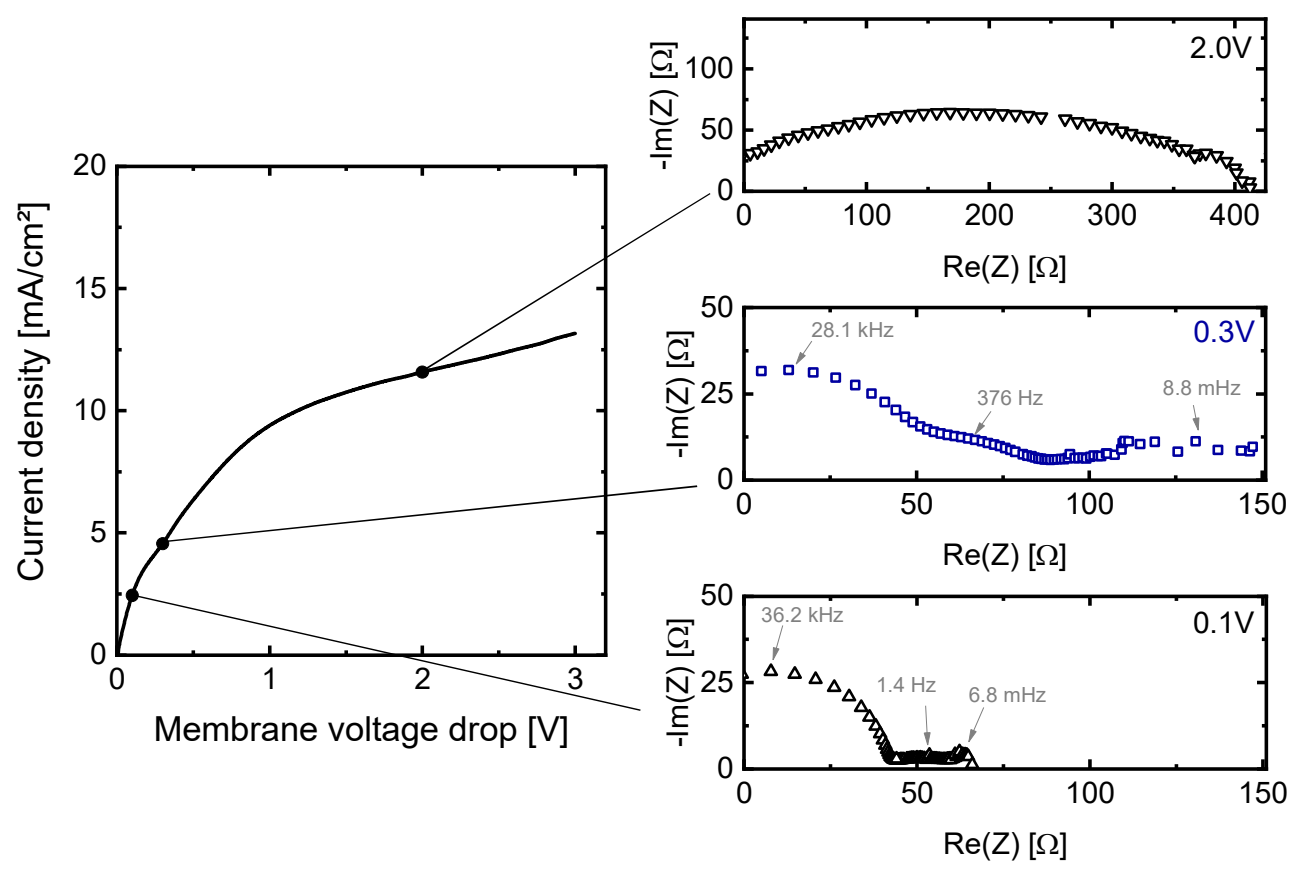

Figure 7: Current-voltage curve and EIS spectra obtained at different current regimes for $0.05 \mathrm{M} \mathrm{Na}_{2} \mathrm{Ox}$ solutions with a $\mathrm{pH}$ of 6.8 .

with a higher number of species, as compared with $\mathrm{H}_{2} \mathrm{Ox}$.

In contrast with the EIS results registered for strong electrolytes, the arcs showing up at middle frequencies in Fig. 6 and Fig. 7 indicate that additional mass transfer phenomena take place during ED of organic acids. Such phenomena occur at characteristic frequencies significantly apart from each other and tend to merge into one arc as the polarization level is increased. Although the arcs becoming visible at increasing DC bias appear at the right side of the Nyquist plots, their characteristic frequencies indicate that the associated phenomena are not related to diffusion-limited mass transfer processes. In similar studies, the emergence of intermediate arcs at 
increasing currents has been attributed to a Gerischer impedance associated with the progress of the catalyzed water dissociation reaction[44, 45]. The results obtained in our study point in the same direction, as revealed in Fig. 5 for $\mathrm{NaCl}$ solutions. However, $\mathrm{pH}$ could be only measured in the bulk solution, where changes smaller than 0.5 units of $\mathrm{pH}$ were obtained. Harding et al. also reported similar impedance spectra when investigating the dielectric response of rotating disc electrodes with coupled electrochemical and homogeneous reactions [46].

Nonetheless, our impedance results differ from previous works in the fact that, not only one additional arc evolves at intermediate frequencies, but at least, two additional arcs are registered. In this regard, $\mathrm{OH}^{-}$and $\mathrm{H}^{+}$ ions generated at the membrane-solution interfacedo not seem to be the only species transported through the membranes in the range of current densities between $i_{l i m 1}$ and $i_{l i m 2}$. While $\mathrm{OH}^{-}$ions may migrate through the membrane, the generated $\mathrm{H}^{+}$ions at the diluting membrane solution-interface may contribute to decrease the $\mathrm{pH}$ in the solution layer near the membrane. Experimental measurements showed that $\mathrm{pH}$ changes in the bulk are minimal, so that the solution layer where significant $\mathrm{pH}$ changes occur should be very thin. This hypothesis was also considered by Nikonenko et al. for modelling the transport of carbonic acid anions through anion-exchange membranes [47]. According to the speciation diagrams shown in Fig. 1, even a very small decrease in $\mathrm{pH}$ in a thin solution layer near the diluting membranesolution interface would displace the equilibrium towards the formation of organic anions of lower charge. Simultaneously, the generation of $\mathrm{H}^{+}$and 
a)

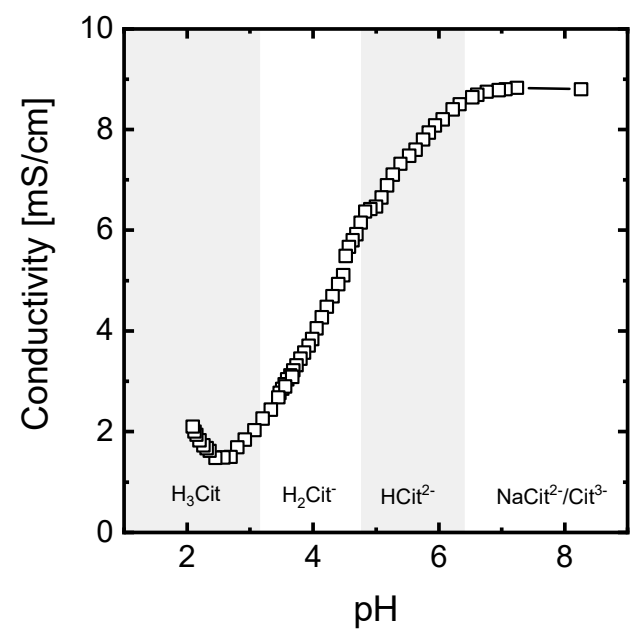

b)

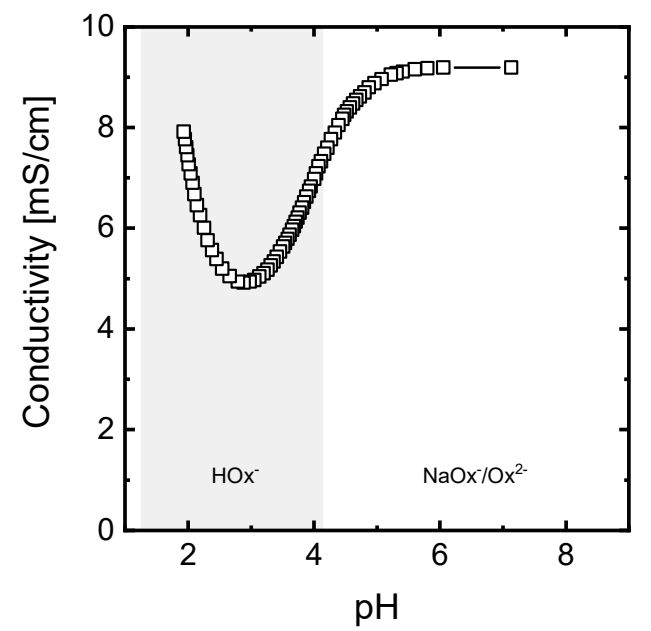

Figure 8: pH-conductivity titration curves obtained for a total anion concentration of $0.05 \mathrm{M}$ with the systems (a) $\mathrm{H}_{3} \mathrm{Cit} / \mathrm{Na}_{3} \mathrm{Cit}$ and (b) $\mathrm{H}_{2} \mathrm{Ox} / \mathrm{Na}_{2} \mathrm{Ox}$. The figures show the relationship between solution $\mathrm{pH}$ and conductivity. Areas of different colors show the regions of predominance of different species.

$\mathrm{OH}^{-}$ionswould concatenate additional homogeneous reactions. Thus, the additional arcs showing up in the Nyquist plots at intermediate frequencies correlate with chain homogeneous reactions triggered by the dissociation of water mediated by the membrane fixed charges.

The impedance results obtained for different DC bias with solutions of $\mathrm{H}_{2} \mathrm{Ox}$ and $\mathrm{H}_{3}$ Cit of lower $\mathrm{pH}$ values are analogous to those obtained for the highest $\mathrm{pH}$ values at low polarization levels (corresponding to the lower-right panel of Fig. 6 and Fig. 7). Thus, solutions of the organic acids at $\mathrm{pH}$ values where the monovalent acid anions (i.e. $\mathrm{HOx}^{-}$and $\mathrm{H}_{2} \mathrm{Cit}^{-}$) predominate in the bulk solution also show a similar behavior as the one described above for strong electrolytes. The absence of multiple Gerischer arcs can be explained 
by the fact that monovalent acid anions can only undergo protonation reactions at very low $\mathrm{pH}$ values, giving rise to non-charged species. On the contrary, at high $\mathrm{pH}$ values, where multivalent anions are the main species in the bulk solution, the generation of a small number of $\mathrm{H}^{+}$ions already implies a change in the predominating species, thus altering the conductivity of the system. The influence of the charge of acid anions on the conductivity of the system can also be deduced from the relationship between solution conductivity and $\mathrm{pH}$ depicted in Fig. 8. The shadowed and white sectors represent the regions of predominance of the different species. Here, it is confirmed that for both systems, when starting from high $\mathrm{pH}$ values, the formation of monovalent anions at decreasing $\mathrm{pH}$ is accompanied by a decrease in conductivity. Furthermore, the decrease in conductivity is consistent with the concatenation of equilibrium reactions and the conversion of multivalent anions into monovalent ones. In other words, once water molecules are strongly polarized near the membrane fixed charges, the resulting $\mathrm{H}^{+}$ions migrate towards the cathode, finding on their way acid anions and displacing reactions (2), (3) or (6) towards the left. This correlation results especially evident for the $\mathrm{H}_{2} \mathrm{Ox} / \mathrm{Na}_{2} \mathrm{Ox}$ system, since the minimum in conductivity at a $\mathrm{pH}$ of 2.7 coincides with the maximum proportion of $\mathrm{HOx}^{-}$anions in the speciation diagrams of Fig. 1(b). Therefore, the change in ionic conductivity of the thin reaction layer near the membrane, along with the reaction impedance, add up to the intensification of concentration polarization and explain the formation of the tilted plateaus at current densities between $i_{l i m 1}$ and $i_{l i m 2}$. The progressive depletion of acid species results in the subsequent bending of the polarization curves at $i_{l i m 2}$. 


\section{Conclusions}

Transport of citric and oxalic acid solutions through anion-exchange membranes has been investigated via multiple electrochemical measurement techniques. Here, we have addressed the challenge of characterizing the main phenomena responsible for the atypical current-voltage behavior observed in such systems. Results have shown that EIS is a highly informative technique allowing it to probe relatively fast reactions triggered by the onset of catalytic

- Electrodialysis of organic acids conducted in the region of predominance of multiply charged anions is characterized by the registration of current-voltage curves with two $i_{\text {lim }}$. An increase in the system resistance at current densities between $i_{\lim 1}$ and $i_{\lim 2}$ is manifested in the form of a tilted plateau in the curves. Consequently, the first limiting current density cannot be ascribed to the complete exhaustion of ions near the membrane surface.

- The timely resolution of conventional dynamic techniques, such as chronopotentiometry, is not sufficient for elucidating the phenomenon causing the first plateau. In contrast, phenomena taking place within a wide spectrum of frequencies can be accessed via EIS, thus enabling the identification of multiple events of distinct nature contributing to the total system resistance.

- The progress of $\mathrm{H}^{+}$and $\mathrm{OH}^{-}$ions generation, along with homogeneous protonation reactions of weak acid anions, are fingerprinted by multiple Gerischer arcs appearing at intermediate frequencies in Nyquist diagrams. The Gerischer arcs, i.e. homogeneous electrolyte rections, 


\section{Acknowledgement}

M.C. Martí-Calatayud acknowledges the support of Generalitat Valenciana through the funding APOSTD/2017/059.

\section{References}

[1] A. A. Kiss, J. P. Lange, B. Schuur, D. W. Brilman, A. G. van der Ham, S. R. Kersten, Separation technology-Making a difference in biorefineries, Biomass and Bioenergy 95 (2016) 296-309. 
[2] C. Abels, F. Carstensen, M. Wessling, Membrane processes in biorefinery applications, Journal of Membrane Science 444 (2013) 285-317.

[3] Z. Sun, B. Fridrich, A. De Santi, S. Elangovan, K. Barta, Bright Side of Lignin Depolymerization: Toward New Platform Chemicals, Chemical Reviews 118 (2) (2018) 614-678.

[4] M. Wang, J. Ma, H. Liu, N. Luo, Z. Zhao, F. Wang, Sustainable Productions of Organic Acids and Their Derivatives from Biomass via Selective Oxidative Cleavage of C-C Bond, ACS Catalysis 8 (3) (2018) 2129-2165.

[5] A. A. Koutinas, A. Vlysidis, D. Pleissner, N. Kopsahelis, I. Lopez Garcia, I. K. Kookos, S. Papanikolaou, T. H. Kwan, C. S. K. Lin, Valorization of industrial waste and by-product streams via fermentation for the production of chemicals and biopolymers, Chemical Society Reviews $43(8)(2014) 2587$.

[6] E. Betiku, H. A. Emeko, B. O. Solomon, Fermentation parameter optimization of microbial oxalic acid production from cashew apple juice, Heliyon 2 (2016) e00082.

[7] L. Regestein, T. Klement, P. Grande, D. Kreyenschulte, B. Heyman, T. Maßmann, A. Eggert, R. Sengpiel, Y. Wang, N. Wierckx, L. M. Blank, A. Spiess, W. Leitner, C. Bolm, M. Wessling, A. Jupke, M. Rosenbaum, J. Büchs, From beech wood to itaconic acid: Case study on biorefinery process integration, Biotechnology for Biofuels 11 (1) (2018) 1-11. 
[8] D. Di Marino, T. Jestel, C. Marks, J. Viell, M. Blindert, S. M. Kriescher, A. C. Spiess, M. Wessling, Carboxylic Acids Production via Electrochemical Depolymerization of Lignin, ChemElectroChem 6 (5) (2019) $1434-1442$.

[9] C. S. López-Garzón, A. J. J. Straathof, Recovery of carboxylic acids produced by fermentation, Biotechnology Advances 32 (5) (2014) 873904.

[10] L. Handojo, A. K. Wardani, D. Regina, C. Bella, M. T. Kresnowati, I. G. Wenten, Electro-membrane processes for organic acid recovery, RSC Advances 9 (14) (2019) 7854-7869.

[11] C. Jiang, Y. Wang, T. Xu, Membranes for the recovery of organic acids from fermentation broths, in: A. Figoli, A. Cassano, A. Basile (Eds.), Membrane Technologies for Biorefining, Woodhead Publishing, Duxford (UK), 2016, pp. 135-161.

[12] J. Stodollick, R. Femmer, M. Gloede, T. Melin, M. Wessling, Electrodialysis of itaconic acid: A short-cut model quantifying the electrical resistance in the overlimiting current density region, Journal of Membrane Science 453 (2014) 275-281.

[13] E. Brauns, Towards a worldwide sustainable and simultaneous largescale production of renewable energy and potable water through salinity gradient power by combining reversed electrodialysis and solar power?, Desalination 219 (1-3) (2008) 312-323. 
[14] S. Abu Khalla, M. Suss, Desalination via chemical energy: An electrodialysis cell driven by spontaneous electrode reactions, Desalination 467 (April) (2019) 257-262.

[15] A. Chandra, J. G. D. Tadimeti, S. Chattopadhyay, Transport hindrances with electrodialytic recovery of citric acid from solution of strong electrolytes, Chinese Journal of Chemical Engineering 26 (2) (2018) 278292.

[16] S. J. Andersen, T. Hennebel, S. Gildemyn, M. Coma, J. Desloover, J. Berton, J. Tsukamoto, C. Stevens, K. Rabaey, Electrolytic Membrane Extraction Enables Production of Fine Chemicals from Biorefinery Sidestreams, Environmental science \& technology 48 (2014) 71357142 .

[17] R. J. Jones, J. Massanet-Nicolau, A. Guwy, G. C. Premier, R. M. Dinsdale, M. Reilly, Removal and recovery of inhibitory volatile fatty acids from mixed acid fermentations by conventional electrodialysis, Bioresource Technology 189 (2015) 279-284.

[18] P. Chai, J. Wang, H. Lu, The cleaner production of monosodium lglutamate by resin-filled electro-membrane reactor, Journal of Membrane Science 493 (2015) 549-556.

[19] L. Fu, X. Gao, Y. Yang, F. Aiyong, H. Hao, C. Gao, Preparation of succinic acid using bipolar membrane electrodialysis, Separation and Purification Technology 127 (2014) 212-218. 
[20] M. Kumar, B. P. Tripathi, V. K. Shahi, Electro-membrane reactor for separation and in situ ion substitution of glutamic acid from its sodium salt, Electrochimica Acta 54 (21) (2009) 4880-4887.

[21] N. Pismenskaya, V. Nikonenko, B. Auclair, G. Pourcelly, Transport of weak-electrolyte anions through anion exchange membranes, Journal of Membrane Science 189 (1) (2001) 129-140.

[22] M. Martí-Calatayud, D. C. Buzzi, M. García-Gabaldón, E. Ortega, A. M. Bernardes, J. A. S. Tenório, V. Pérez-Herranz, Sulfuric acid recovery from acid mine drainage by means of electrodialysis, Desalination 343 (2014) 120-127.

[23] M. C. Martí-Calatayud, D. C. Buzzi, M. García-Gabaldón, A. M. Bernardes, J. A. S. Tenório, V. Pérez-Herranz, Ion transport through homogeneous and heterogeneous ion-exchange membranes in single salt and multicomponent electrolyte solutions, Journal of Membrane Science 466 (2014) 45-57.

[24] E. D. Belashova, N. D. Pismenskaya, V. V. Nikonenko, P. Sistat, G. Pourcelly, Current-voltage characteristic of anion-exchange membrane in monosodium phosphate solution. Modelling and experiment, Journal of Membrane Science 542 (2017) 177-185.

[25] M. C. Martí-Calatayud, M. García-Gabaldón, V. Pérez-Herranz, Mass Transfer Phenomena during Electrodialysis of Multivalent Ions: Chemical Equilibria and Overlimiting Currents, Applied Sciences 8 (9) (2018) 1566. 
[26] E. D. Melnikova, N. D. Pismenskaya, L. Bazinet, S. Mikhaylin, V. V. Nikonenko, Effect of ampholyte nature on current-voltage characteristic of anion-exchange membrane, Electrochimica Acta 285 (2018) 185-191.

[27] O. Rybalkina, K. Tsygurina, E. Melnikova, S. Mareev, I. Moroz, Partial Fluxes of Phosphoric Acid Anions through Anion-Exchange Membranes in the Course of NaH 2 PO 4 Solution Electrodialysis, International Journal of Molecular Sciences 20 (3593) (2019) 1-22.

[28] R. Femmer, A. Mani, M. Wessling, Ion transport through electrolyte/polyelectrolyte multi-layers, Scientific Reports 5 (2015) 11583.

[29] T. Belloň, P. Polezhaev, L. Vobecká, M. Svoboda, Z. Slouka, Experimental observation of phenomena developing on ion-exchange systems during current-voltage curve measurement, Journal of Membrane Science 572 (November 2018) (2019) 607-618.

[30] O. A. Rybalkina, K. A. Tsygurina, E. D. Melnikova, G. Pourcelly, V. V. Nikonenko, N. D. Pismenskaya, Catalytic effect of ammonia-containing species on water splitting during electrodialysis with ion-exchange membranes, Electrochimica Acta 299 (2019) 946-962.

[31] Y. Tanaka, Water dissociation reaction generated in an ion exchange membrane, Journal of Membrane Science 350 (1-2) (2010) 347-360.

[32] E. I. Belova, G. Y. Lopatkova, N. D. Pismenskaya, V. V. Nikonenko, C. Larchet, G. Pourcelly, Effect of anion-exchange membrane surface properties on mechanisms of overlimiting mass transfer, Journal of Physical Chemistry B 110 (27) (2006) 13458-13469. 
[33] E. Belova, G. Lopatkova, N. Pismenskaya, V. Nikonenko, C. Larchet, Role of water splitting in development of electroconvection in ionexchange membrane systems, Desalination 199 (1-3) (2006) 59-61.

[34] V. I. Zabolotskiy, A. Y. But, V. I. Vasil'eva, E. M. Akberova, S. S. Melnikov, Ion transport and electrochemical stability of strongly basic anion-exchange membranes under high current electrodialysis conditions, Journal of Membrane Science 526 (November 2016) (2017) 60-72.

[35] D. Harvey, Modern analytical chemistry, mcgraw-hill Edition, McGrawHill, Boston, 2000.

[36] M. Papagianni, Advances in citric acid fermentation by Aspergillus niger: Biochemical aspects, membrane transport and modeling, Biotechnology Advances 25 (3) (2007) 244-263.

[37] P. Komáromy, P. Bakonyi, A. Kucska, G. Tóth, L. Gubicza, K. BélafiBakó, N. Nemestóthy, Optimized pH and Its Control Strategy Lead to Enhanced Itaconic Acid Fermentation by Aspergillus terreus on Glucose Substrate, Fermentation 5 (2) (2019) 31.

[38] M. C. Martí-Calatayud, M. García-Gabaldón, V. Pérez-Herranz, Study of the effects of the applied current regime and the concentration of chromic acid on the transport of $\mathrm{Ni}^{2+}$ ions through Nafion $117 \mathrm{mem}-$ branes, Journal of Membrane Science 392-393 (2012) 137-149.

[39] M. C. Martí-Calatayud, M. García-Gabaldón, V. Pérez-Herranz, Effect of the equilibria of multivalent metal sulfates on the transport 
through cation-exchange membranes at different current regimes, Journal of Membrane Science 443 (2013) 181-192.

[40] D. Y. Butylskii, S. A. Mareev, N. D. Pismenskaya, P. Y. Apel, O. A. Polezhaeva, V. V. Nikonenko, Phenomenon of two transition times in chronopotentiometry of electrically inhomogeneous ion exchange membranes, Electrochimica Acta 273 (2018) 289-299.

[41] A. A. Moya, Electrochemical Impedance of Ion-Exchange Membranes with Interfacial Charge Transfer Resistances, The Journal of Physical Chemistry C (2016) acs.jpcc.5b12087.

[42] R. Femmer, M. C. Martí-Calatayud, M. Wessling, Mechanistic modeling of the dielectric impedance of layered membrane architectures, Journal of Membrane Science 520 (2016) 29-36.

[43] F. Roghmans, M. C. Martí-Calatayud, S. Abdu, R. Femmer, R. Tiwari, A. Walther, M. Wessling, Electrochemical impedance spectroscopy fingerprints the ion selectivity of microgel functionalized ion-exchange membranes, Electrochemistry Communications 72 (2016) 113-117.

[44] E. Kniaginicheva, N. Pismenskaya, S. Melnikov, E. Belashova, P. Sistat, M. Cretin, V. Nikonenko, Water splitting at an anion-exchange membrane as studied by impedance spectroscopy, Journal of Membrane Science 496 (2015) 78-83.

[45] N. D. Pismenskaya, E. V. Pokhidnia, G. Pourcelly, V. V. Nikonenko, Can the electrochemical performance of heterogeneous ion-exchange mem- 
branes be better than that of homogeneous membranes?, Journal of Membrane Science 566 (June) (2018) 54-68.

[46] M. S. Harding, B. Tribollet, V. Vivier, M. E. Orazem, The Influence of Homogeneous Reactions on the Impedance Response of a Rotating Disk Electrode, Journal of The Electrochemical Society 164 (11) (2017) E3418-E3428.

[47] V. Nikonenko, K. Lebedev, J. A. Manzanares, G. Pourcelly, Modelling the transport of carbonic acid anions through anion-exchange membranes, Electrochimica Acta 48 (24) (2003) 3639-3650. 